\title{
CHRONIC PROGRESSIVE EXTERNAL OPHTHALMOPLEGIA IS ASSOCIATED WITH A NOVEL MUTATION IN THE MITOCHONDRIAL TRNA ${ }^{\text {Asn }}$ GENE
}

\author{
Peter Seibel ${ }^{1, *}$, Jürgen Lauber ${ }^{2}$, Thomas Klopstock ${ }^{1}$, Ceçile Marsac ${ }^{3}$, \\ Bernhard Kadenbach ${ }^{4}$ and Heinz Reichmann ${ }^{\prime}$
}

\footnotetext{
${ }^{1}$ Neurologische Universitätsklinik, Josef-Schneider-Straße 11, 97080 Würzburg, Germany

2 Institut für Molekularbiologie und Tumorforschung, Emil-Mannkopff-Straße 2, 35037 Marburg, Germany

${ }^{3}$ Laboratoire de Biochimie, INSERM U. 75, 156 Rue de Vaugirard, 75730 Paris, France

${ }^{4}$ Fachbereich Chemie der Philipps-Universität, Hans-Meerwein-Straße, 35043 Marburg, Germany
}

Received September 5, 1994

Chronic progressive external ophthalmoplegia (CPEO) is caused by a decreased oxidative phosphorylation (OXPHOS) activity due to large-scale deletions of the mitochondrial genome in $50 \%$ of the patients. The deletions encompass structural OXPHOS genes as well as tRNA genes, required for their expression so that the pathogenesis could be due to the deleted OXPHOS subunits or to an impaired mitochondrial translation. We have analyzed the mitochondrial genome of a patient presenting with CPEO for single base substitutions and discovered a novel heteroplasmic mutation in the RNA $^{\text {Asn }}$ gene at position 5692 that converts a highly conserved adenine into a guanine. This mutation is unique because it is located at the transition of the anticodon loop to the anticodon stem and it leads to an additional base pair, thus reducing the number of loop-forming nucleotides from seven to five. Our findings suggest that CPEO can be caused by a single base substition in a mitochondrial tRNA gene so that the mitochondrial protein synthesis becomes the rate limiting step in OXPHOS fidelity. 1994 Academic Press, Inc.

Chronic progressive external ophthalmoplegia (CPEO) and Kearns-Sayre syndrome (KSS) have been shown to fulfill the criteria for mitochondrial DNA (mtDNA) mutation. The disease is either sporadic (1) or maternally inherited (2), although autosomal inheritance has been reported (3). It is associated with severe defects of the oxidative phosphorylation (OXPHOS) complexes I, III, IV and V (4-6), subunits of which are encoded by the mitochondrial DNA (7). The severity

* To whom correspondence should be addressed. 
of patient's symptoms varies, consistent with a mitotic or meiotic segregation of a heteroplasmic mutated mtDNA. Finally, as the patient's mitochondrial ATP-generating capacity declines, tissues of the central nervous system, skeletal muscle and heart are progressively affected, indicating that tissue-specific energetic thresholds are being traversed by the shift of heteroplasmy towards mutated mitochondrial DNA (8). Genetically, the OXPHOS system is expressed under the combined control of the nuclear and the mitochondrial genome (7) that codes for seven subunits of complex I (NADH-ubiquinol oxidoreductase), one subunit of complex III (ubiquinol-cytochrome c oxidoreductase), three subunits of complex IV (cytochrome c oxidase) and two subunits of complex V (ATP synthase). Additionally, it harbors the $12 \mathrm{~S}$ and $16 \mathrm{~S}$ rRNA genes, as well as a set of 22 tRNAs, required for the expression of the OXPHOS genes. Detailed RFLP-analyses of patients with CPEO revealed heteroplasmic length variations of the mitochondrial genome $(1,9,10)$. The most frequent "common deletion" spans $4977 \mathrm{bps}$, covering genes for complex I, IV and V as well as tRNA genes for glycine, arginine, histidine, serine and leucine $(1,11)$. Thus, the pathogenicity of mtDNA deletions causing CPEO could be due to three different processes: first, the deletion encompasses structural OXPHOS genes, so that depending on the degree of heteroplasmy within single mitochondria, deleted OXPHOS subunits cannot be synthesized (homoplasmic deleted genomes) or will be synthesized not in the required stoichiometries. Second, deletions generate fusion genes, so that expressed chimeric OXPHOS proteins could interfere with the assembly and functioning of the complexes. Third, besides the structural OXPHOS genes, the deletions always comprise essential tRNA genes. As a result of deleted genomes within single mitochondria, a decreased protein synthesis rate could cause the described OXPHOS deficiencies in patients with CPEO. Compatible with the latter described pathogenicity of mtDNA deletions is the recent observation that the mitochondrial tRNA $^{\text {Leu }}$ mutation at nucleotide pair 3243 , previously attributed to cause mitochondrial encephalomyopathy, lactic acidosis and stroke-like episodes (MELAS), can be associated with progressive external ophthalmoplegia (PEO) (12). In fact, it has been demonstrated that mutations in tRNA genes lead to an impaired mitochondrial protein synthesis in cultured cells of patients with myoclonic epilepsy and ragged-red fibers disease (MERRF) (13) and MELAS (14). This led us to the hypothesis that CPEO could be caused by yet unknown deleterious base substitution in mitochondrial genes essential for functional translation, mimicring a depleted tRNA caused by a mtDNA deletion. Data presented in this paper support this speculation. By sequencing the mitochondrial genome of a patient presenting clinically with CPEO (without length variation), we identified a novel heteroplasmic single base replacement that changes an $\mathrm{A}$ to a $G$ in the anticodon loop of the tRNA ${ }^{\text {Asn }}$. This mutation, located near to the origin of light strand replication, converts a highly conserved nucleotide at position 5692 and was neither found in six unrelated caucasian controls nor in any other population studied so far (15-17). Thus, the 
mutation could account for the pleiotropic phenotypic and biochemical characteristics associated with the disease.

\section{MATERIALS AND METHODS}

Patient. The patient had ophthalmoplegia, muscle weakness of the lower limbs, a severe neuropathy, cerebellar signs and beginning cardiac dysfunction. Biochemically, there was a slight reduction of complexes I and IV of the respiratory chain. Histochemically, a few ragged-red fibers appeared on Gomori trichrome staining.

Isolation of genomic DNA. Total DNA was prepared from about $100 \mathrm{mg}$ of frozen muscle biopsy specimens by the method of Seibel et al. (13).

Southern blot analysis. Two micrograms of total DNA were digested with Pvu II or Bam HI, electrophoresed on a $0.5 \%$ agarose gel and transferred onto nylon membranes (18). The filters were hybridized to a random primer-extended probe generated from mtDNA isolated from human placenta.

Polymerase chain reaction. PCR was used to generate mitochondrial DNA fragments for sequencing and for the detection of mutated and wild-type mtDNA by RFLP analysis (19). Asymmetrically PCR-amplified DNA for dideoxynucleotide chain-terminating sequencing was prepared by adding one primer in 100-fold excess of the other (molar ratio: $30 \mathrm{pmol}: 0.3 \mathrm{pmol}$ ). Primers used for amplification and sequencing. Forward primers annealed to nucleotides (nt) 534-553, 1562-1581, 3007-3023, 3951-3970, 5317-5333, 7392-7410, 8150-8166, 9911- 9932, 11979-11995, 14407-14424, 15553-15569, whereas reverse primers were located at nucleotides 725-706, 1696-1677, 3717-3701, 4508-4489, 6263-6247, 7608-7588, 8628-8608, 10728-10712, $12576-12557,15153-15135,16159-16142$ of the published sequence (7).

DNA sequencing. Sequencing primers were annealed to single-stranded DNA generated by asymmetric PCR and segenced as described by Shoffner et al. (8).

RFLP analysis. $500 \mathrm{ng}$ of PCR-generated DNA amplified with the forward primer annealing to nt $4828-4848$ and a reverse primer located at nt $6266-6246$ was purified by precipitation and digested with the restriction endonuclease $\mathrm{HpaI}(10$ units) for $3 \mathrm{~h}$. The DNA fragments were resolved on a $1.2 \%$ agarose gel and visualized by ethidium bromide staining under UV light.

Quantification of heteroplasmic mtDNA. Heteroplasmic mtDNA was quantificated by the modified method of Seibel et al. (20). After 25 cycles, PCR was interrupted, supplemented with ${ }^{32} \mathrm{P}$-labeled dATP and restarted for an extra cycle, followed by Hpa I-RFLP analysis. DNA-fragments were excised from an agarose gel and quantificated by counting the ${ }^{32} \mathrm{P}$ radiation using a liquid scintillation counter.

\section{RESULTS}

Southern blot analysis of patient's genomic DNA revealed no major length alteration (>1.5 kb) of the mitochondrial genome, as the mtDNA formed only a single band of $16.5 \mathrm{~kb}$ in size. Further restriction endonuclease mapping of the genomic DNA excluded also small mtDNA deletions ( $>0.3 \mathrm{~kb}$, data not shown). To study if any gene of the mitochondrial encoded translation apparatus was altered, the mitochondrial genome of the patient was amplified in 11 fragments (encompassing all tRNA and rRNA genes) and sequenced. A mutation was found at position 5692 (see fig. 1a, left panel), almost 40 nucleotides upstream of the origin of light strand mtDNA replication. The mutation appeared heteroplasmically upon sequence analysis. To determine if this mutation contributes to the pathogenicity of the disease, the same region was sequenced from a control subject, whose DNA sequence revealed exclusively the wild-type 
adenine at this location (see fig. 1a, right panel). This analysis was extended to additional patients and controls by utilizing the restriction endonuclease $H p a$ I. This enzyme cleaves the wild-type sequence (GTTAAC), while the mutated sequence (GTTAGC) is not altered. Hpa IRFLP analysis of PCR-generated DNA fragments resulted in fragments of $863 \mathrm{bp}$ and $575 \mathrm{bp}$ in case of wild-type mtDNA, but in an unaltered fragment of $1438 \mathrm{bp}$ in the case of the mutation. The patient's DNA was analyzed together with six unrelated caucasian controls. While the patient's analysis revealed mutated and wild-type mtDNA (heteroplasmy), as expected from the sequence analysis, the mutation was not found in the controls (see fig. 1b). Furthermore, the test failed to detect the mutation in twelve unrelated CPEO patients without deletions. Using this test in a quantitative manner, the mitochondrial genotype of the patient was estimated with about $56 \%$ mutated and $44 \%$ wild-type mtDNA.

To assess the functional significance of nucleotide pair 5692, we aligned the human tRNA ${ }^{\text {Asn }}$ with the sequences from other species (see fig. 2a) relative to conserved stem regions (21). In

a
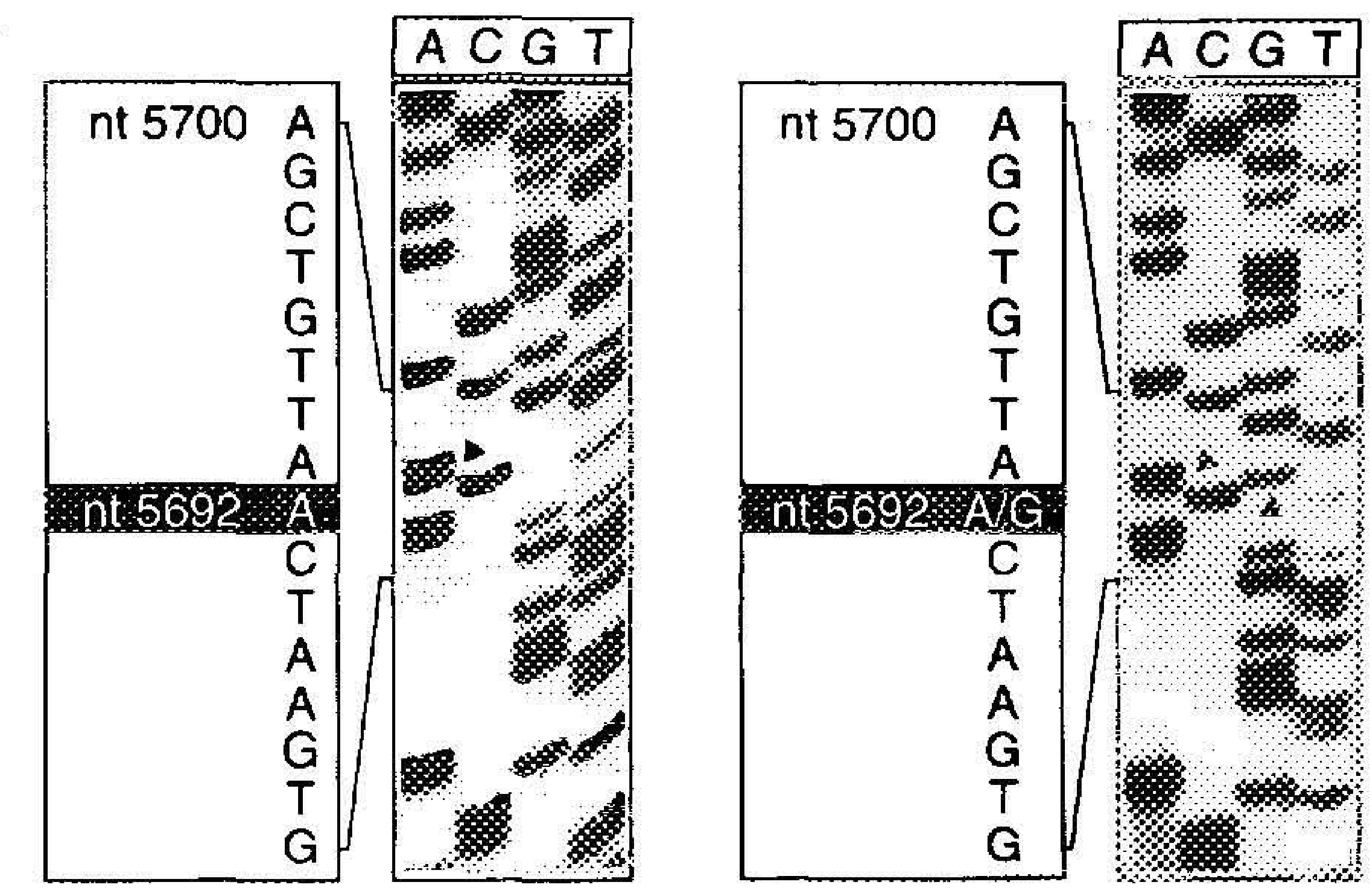

b
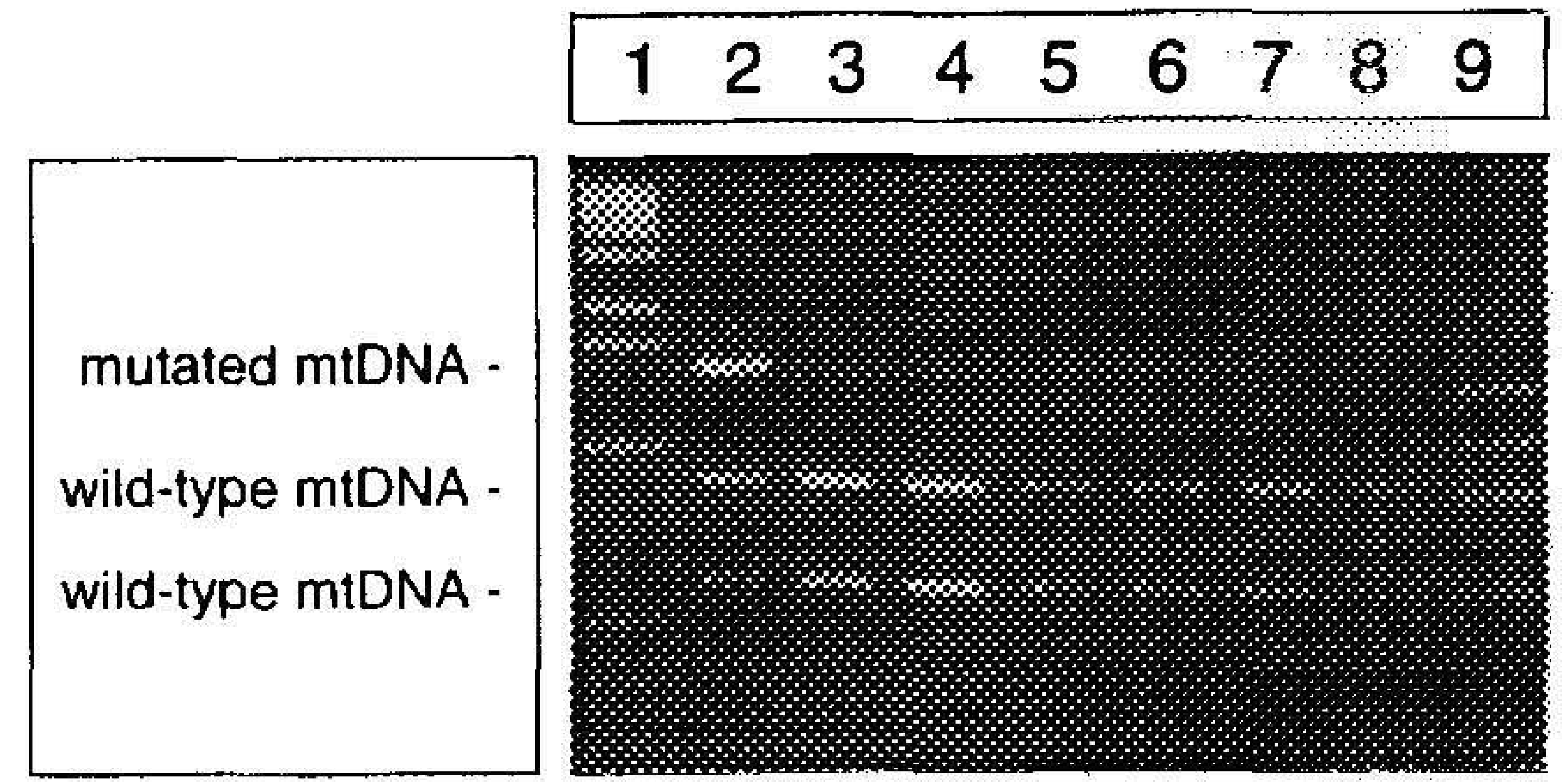

Figure 1. Sequence and Hpa I-RFLP analysis of the mutated and the wild-type mttRNA $A^{A s n}$-gene. a: The arrows indicate nucleotide 5692 of the human mitochondrial genome (7). Left panel: wild-type sequence of a control subject; right panel: heteroplasmic mutated mtDNA of a patient presenting with CPEO. $\boldsymbol{b}$ : Mutated mtDNA results in an unaltered fragment of $1438 \mathrm{bp}$, whereas the wild-type mtDNA is cleaved into two fragments of $863 \mathrm{bp}$ and $575 \mathrm{bp}$. Lane 1: molecular weight marker X (Boehringer Mannheim); lane 2: patient with CPEO; lanes 3-8: caucasian controls; lane 9: molecular weight marker $\Phi$ X174 RF DNA digested with Hae III (New England Biolabs). 
this alignment, the A was present in all other species from rat to sea urchin. Hence, nucleotide 5692 of the anticodon loop appears to be functionally conserved and its substitution could affect tRNA ${ }^{\text {Asn }}$ function.

To illustrate how the function of the mutated tRNA could be affected, we studied the structural changes taking place in the anticodon loop of the mutated tRNA ${ }^{A s n}$. As was predicted by computer analysis (22), the wild-type mttRNA ${ }^{\mathrm{Asn}}$ forms a clover-leaf structure with an anticodon loop of seven unmatched nucleotides, whereas its anticodon stem is formed by five base pairs (see fig. $2 b$ ). The energy released during formation of stem and loop was estimated under standardized conditions $\left[1 \mathrm{M} \mathrm{Na}^{+} ; \mathrm{pH}=7.0 ; \mathrm{T}=298.15 \mathrm{~K}\right]$ with $-11.1 \mathrm{~kJ} / \mathrm{mol}(23,24)$. The same analysis carried out for the mutated $t R N A^{\text {Asn }}$ led to a reorganization of the anticodon loop, as the mutated nucleotide forms now an additional hybrid pair with its counterpart. Therefore, the number of loop-forming nucleotides is decreased by two so that only five bases remain, whereas the stem is extended by an extra base pair. This results in an energy release of totally -30.5 $\mathrm{kJ} / \mathrm{mol}$. As a consequence of the extra base pair formation, a further hybrid could be formed by the next couple of bases (see fig. $2 b$ ), leading to an extra extension of the stem by one base pair (total length: seven base pairs) so that only three bases remain to form the anticodon loop. The energy release for this formation is estimated with $-23.0 \mathrm{~kJ} / \mathrm{mol}$.

\section{DISCUSSION}

The association of CPEO and KSS with large scale deletions of the mitochondrial genome has been reported before $(1,9,10)$. However, this accounts only for $50 \%$ of the cases, the molecular basis of the others remains unclear, although an association of the MELAS mutation at nucleotide pair 3243 has been reported for patients with PEO (12). The classical CPEO genotype (mtDNA deletion) results in a reduced OXPHOS activity. The pathogenic mechanism leading to the reduction is poorly understood and has been discussed controversely in the literature $(25,26)$. Most likely, the reduction of respiratory chain activity is due to the impaired mitochondrial translation rate caused by the deleted tRNA genes. If so, a mutation in a mitochondrial gene of the protein synthesis apparatus could result in a similar OXPHOS deficiency. Thus, we searched for a mutation in the mitochondrial genome of a patient with CPEO presenting no length variation that could explain similar pleiotropic phenotypic and biochemical alterations (biochemically: slightly reduced activity of complex I and IV, histochemically: ragged-red fibers). Only a single heteroplasmic nucleotide conversion was detected in this patient, which met all the criteria expected for a mutation causing CPEO: first, it is the only mutation in the sequenced tRNA and rRNA genes that alters a highly conserved element (see fig. 2a). Second, it correlates perfectly with the disease: it was only found in the patient's genome and has not been found in our caucasian controls. Our data are corroborated by population genetic studies: Hpa I 
a

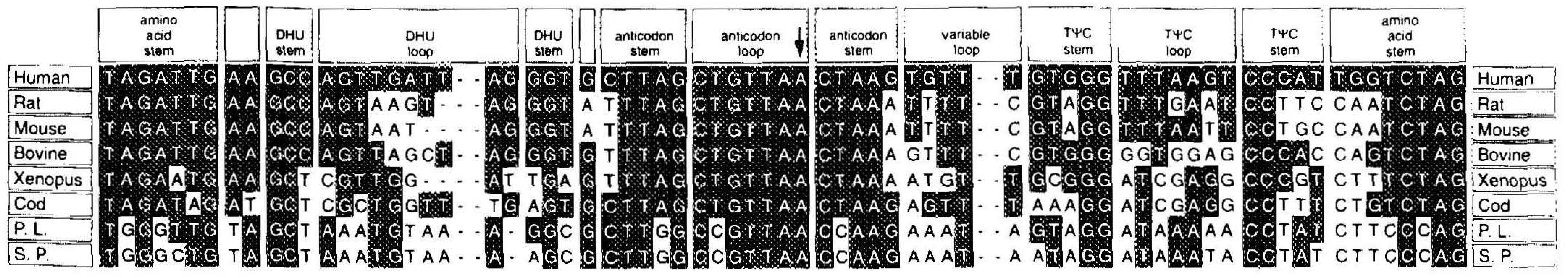

b

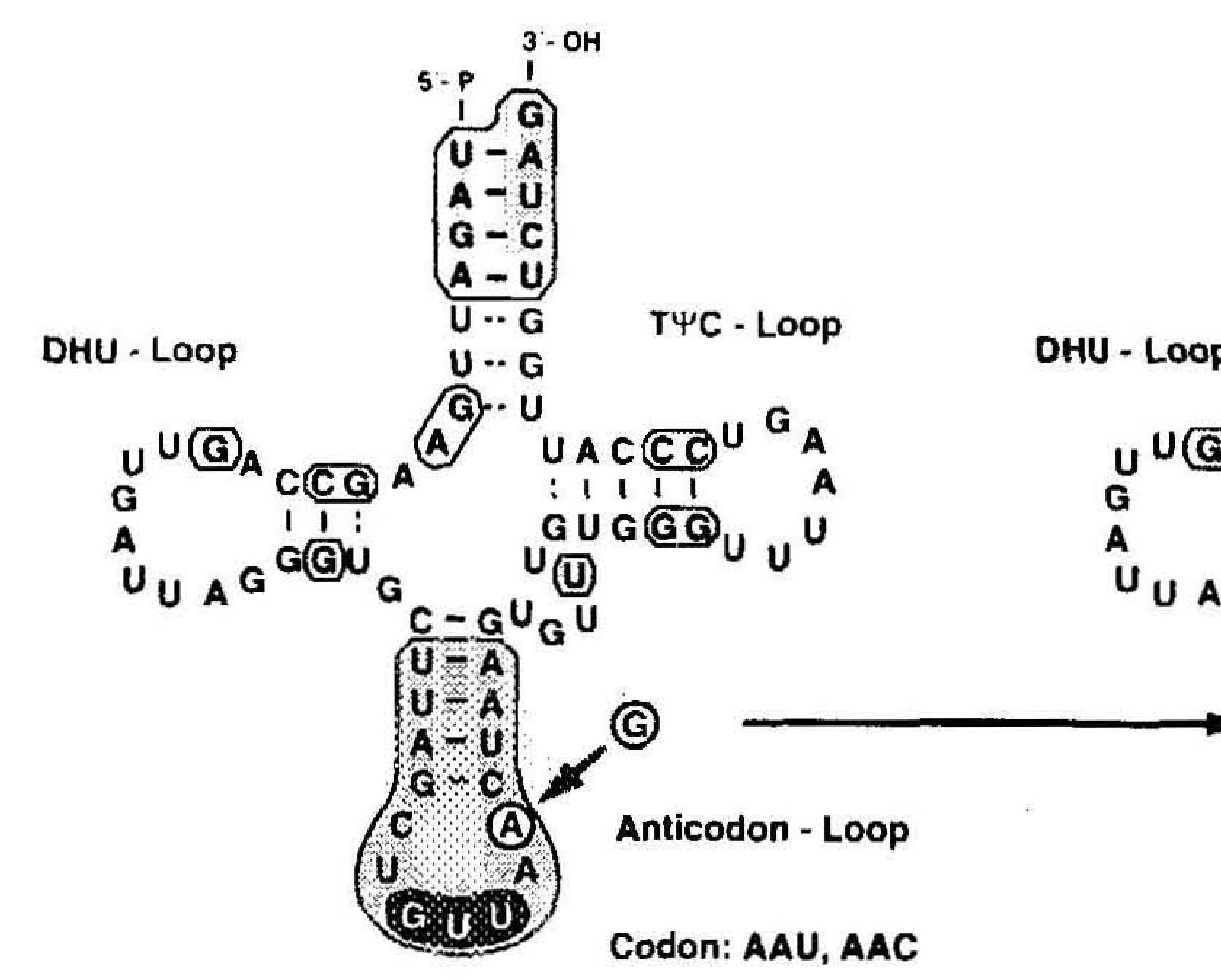

$d G^{\circ}[$ anticodon stem $+100 \mathrm{p}]=-\mathbf{1 1 . 1} \mathrm{kJ} / \mathrm{mol}$

$\mathrm{dG}^{0}[$ anticodon stem + loop] $=-30.4 \mathrm{~kJ} / \mathrm{mol}$

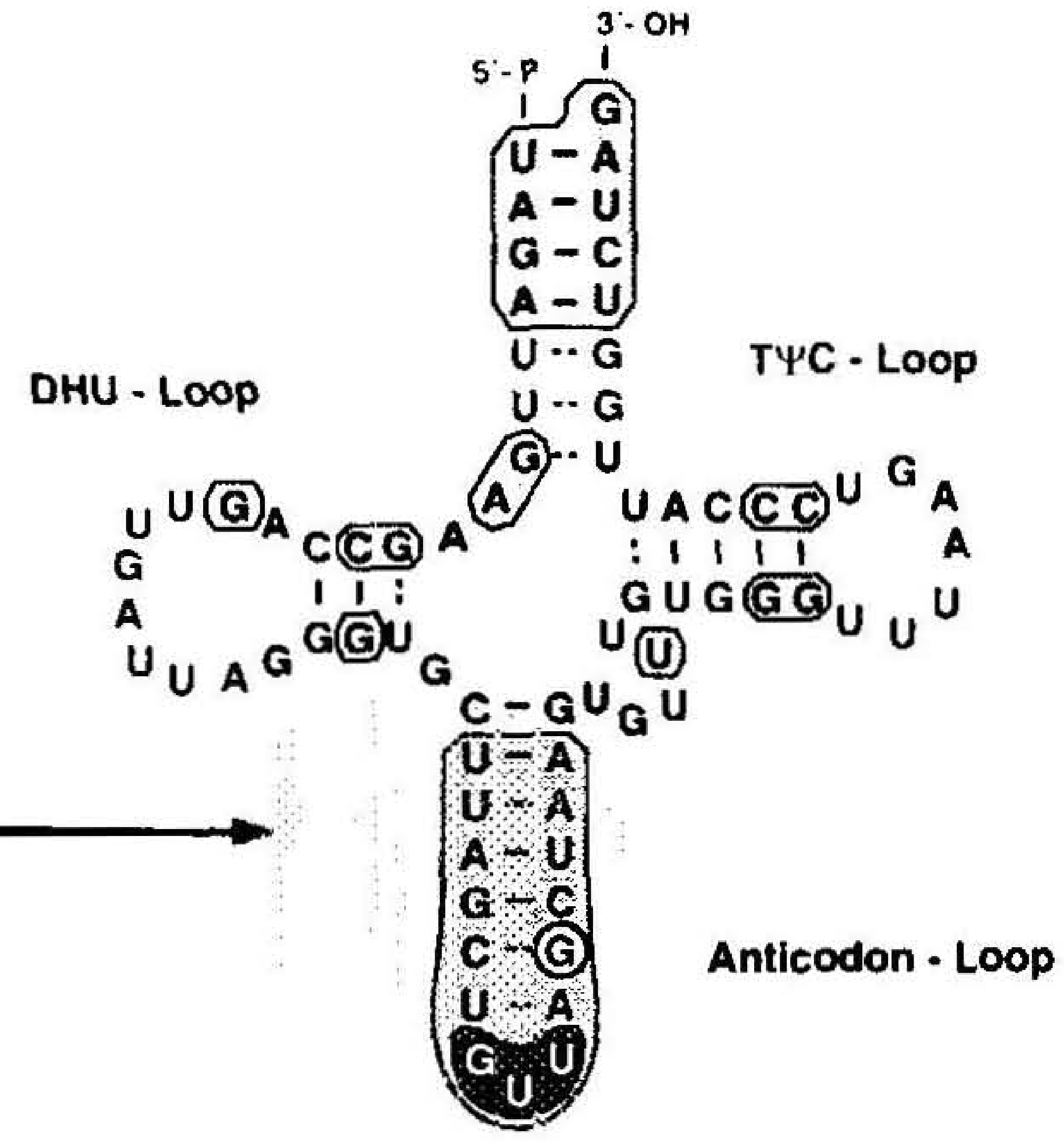

$d G^{\circ}[a n t i c o d o n$ stem + loop $]=-23.0 \mathrm{~kJ} / \mathrm{mol}$

Figure 2. Interspecies alignment of the mitochondrial $t R N A^{A s n}$-genes and the predicted secondary structure of the wild-type and mutated mttRNA $A^{A . n}$

a: Shaded areas are bases homologous to the human sequence. Bases are grouped according to their function within the tRNA (21). The arrow indicates the mutated nucleotide. P. L.:

Paracentrotus lividus; S. P.: Strongylocentrotus purpuratus. b: Shaded areas represent highly conserved nucleotides between human, rat, mouse, bovine, xenopus and cod. The inversely displayed nucleotides define the anticodon (GUU). 
is widely used in RFLP analysis and so far, a variation at mtDNA position 5692 has never been observed in any other population (15-17). Third, it alters the tRNA in a way that could explain the decreased OXPHOS activity by a diminished mitochondrial protein synthesis rate. Fourth, it is heteroplasmic, consistent with a recent origin for a mutation. The shift from wild-type to almost complete mutated mtDNA takes place by the slow mechanism of mitotic or meiotic segregation (27). The time required to enforce the mutation to homoplasmy is about four generations (Seibel, unpublished data, estimated from the tRNA ${ }^{\text {leu }}$ mutation at nucleotide pair 3243, previously attributed to MELAS). Thus, the tRNA ${ }^{\text {Asn }}$ mutation at position 5692 fulfills all the criteria predicted for a deleterious mutation and hence is most likely associated with the disease. Furthermore, our findings support the hypothesis that diverse, yet unknown mutations in genes functioning in mitochondrial protein synthesis could contribute to the pathogenicity of CPEO in other cases as well.

The mechanism, how the mutation leads to a decreased respiratory chain activity as a result of an impaired translation, is unclear. Most likely, the secondary structure of the mitochondrial tRNA $^{\text {Asn }}$ is altered so that the tertiary structure of the anticodon loop is displaced. Following thermodynamic rules, systems always try to reach the lowest level of energy. Thus, the predicted tRNA $^{\text {Asn }}$ structure containing five anticodon loop-forming nucleotides is favoured during the formation process of the tRNA. The energy released during this process $\left(\mathrm{dG}^{0}=-30.4 \mathrm{~kJ} / \mathrm{mol}\right)$ is almost identical to the amount of energy released during the hydrolysis of ATP to ADP and phosphate $\left(\mathrm{dG}^{0}=-30.5 \mathrm{~kJ} / \mathrm{mol}\right)$, indicating the stability of the formed loop-stem-structure. Thus, inhibition of assembly of the ribosome-mRNA-tRNA-complex required for a functional translation could be easily explained by the novel tertiary structure of the mutated tRNA ${ }^{\text {Asn }}$. Other pathogenic mechanisms, however, as for instance an incorrect processing of the primary mitochondrial transcript, a malfunctioning modification or editing of tRNA bases, or an incorrect or inhibited loading of the tRNA by the aminoacyl-tRNA-synthetase cannot be excluded.

Analysis of the mitochondrial genes required for functional translation showed that $\mathrm{CPEO}$ could be caused by a single base substitution. This observation suggests that mtDNA deletions causing similar clinical phenotyps may be based on the same pathogenic mechanism. Hence, it is important to consider other yet undiscovered mutations in mitochondrial tRNA or rRNA genes as potential contributors to the pathogenesis of $\mathrm{CPEO}$ and related neuromuscular disorders.

\section{ACKNOWLEDGMENTS}

The excellent technical assistance of Helga Neubauer is gratefully acknowledged. T. K. was a fellow of the Deutsche Forschungsgemeinschaft (Kl 795/1-1). This work was supported in part 
by grants of the Deutsche Forschungsgemeinschaft ( $\operatorname{Re} 265 / 8-2$, awarded to H. R., and Ka 192/17-4, awarded to B. K.) and of the Fritz-Thyssen Stiftung (awarded to B. K.).

\section{REFERENCES}

1. Shoffner, J.M., Lott, M.T., Voljavec, A.S., Soueidan, S.A., Costigan, D.A., and Wallace, D.C. (1989) Proc. Natl. Acad. Sci. U. S. A. 86, 7952-7956.

2. Tanaka, M., Yoneda, M., Ohno, K., Sato, W., Yamamoto, M., Nonaka, I., Horai, S., and Ozawa, T. (1989) J. Inherit. Metab. Dis. 12, 359-362.

3. Zeviani, M., Bresolin, N., Gellera, C., Bordoni, A., Pannacci, M., Amati, P., Moggio, M., Servidei, S., Scarlato, G., and DiDonato, S. (1990) Am. J. Hum. Genet. 47, 904-914.

4. Clark, J.B., Hayes, D.J., Morgan Hughes, J.A., and Byrne, E. (1984) J. Inherit. Metab. Dis. 7 Suppl 1, 62-68.

5. Reichmann, H., Rohkamm, R., Zeviani, M., Servidei, S., Ricker, K., and DiMauro, S. (1986) Arch. Neurol. 43, 957-961.

6. DiMauro, S., Bonilla, E., Zeviani, M., Nakagawa, M., and DeVivo, D.C. (1985) Ann. Neurol. 17, 521-538.

7. Anderson, S., Bankier, A.T., Barrell, B.G., de Bruijn, M.H., Coulson, A.R., Drouin, J., Eperon, I.C., Nierlich, D.P., Roe, B.A., Sanger, F., Schreier, P.H., Smith, A.J., Staden, R., and Young, I.G. (1981) Nature 290, 457-465.

8. Shoffner, J.M., Lott, M.T., Lezza, A.M., Seibel, P., Ballinger, S.W., and Wallace, D.C. (1990) Cell 61, 931-937.

9. Holt, I.J., Harding, A.E., and Morgan Hughes, J.A. (1988) Nature 331, 717-719.

10. Zeviani, M., Moraes, C.T., DiMauro, S., Nakase, H., Bonilla, E., Schon, E.A., and Rowland, L.P. (1988) Neurology 38, 1339-1346.

11. Schon, E.A., Rizzuto, R., Moraes, C.T., Nakase, H., Zeviani, M., and DiMauro, S. (1989) Science 244, 346-349.

12. Moraes, C.T., Ciacci, F., Silvestri, G., Shanske, S., Sciacco, M., Hirano, M., Schon, E.A., Bonilla, E., and DiMauro, S. (1993) Neuromuscul. Disord. 3, 43-50.

13. Seibel, P., Degoul, F., Bonne, G., Romero, N., Francois, D., Paturneau Jouas, M., Ziegler, F., Eymard, B., Fardeau, M., Marsac, C., and Kadenbach, B. (1991) J. Neurol. Sci. 105, 217-224.

14. King, M.P., Koga, Y., Davidson, M., and Schon, E.A. (1992) Mol. Cell Biol. 12, 480-490.

15. Santachiara Benerecetti, A.S., Scozzari, R., Semino, O., Torroni, A., Brega, A., and Wallace, D.C. (1988) Ann. Hum. Genet. 52, 39-56.

16. Scozzari, R., Torroni, A., Semino, O., Sirugo, G., Brega, A., and Santachiara Benerecetti, A.S. (1988) Am. J. Hum. Genet. 43, 534-544.

17. Wallace, D.C. (1989) Cytogenet. Cell Genet. 51, 612-621.

18. Southern, E.M. (1975) J. Mol. Biol. 98, 503-517.

19. Saiki, R.K., Scharf, S., Faloona, F., Mullis, K.B., Horn, G.T., Erlich, H.A., and Arnheim, N. (1985) Science 230, 1350-1354.

20. Seibel, P., Degoul, F., Romero, N., Marsac, C., and Kadenbach, B. (1990) Biochem. Biophys. Res. Commun. 173, 561-565.

21. Sprinzl, M., Hartmann, T., Meissner, F., Moll, J., and Vorderwülbecke, T. (1987) Nucleic. Acids. Res. 15 Suppl, r53-188.

22. Staden, R. (1980) Nucleic. Acids. Res. 8, 817-825.

23. Studnicka, G.M., Rahn, G.M., Cummings, I.W., and Salser, W.A. (1978) Nucleic. Acids. Res. 5, 3365-3387.

24. Salser, W. (1978) Cold Spring Harb. Symp. Quant. Biol. 42 Pt 2, 985-1002.

25. Nakase, H., Moraes, C.T., Rizzuto, R., Lombes, A., DiMauro, S., and Schon, E.A. (1990) Am. J. Hum. Genet. 46, 418-427.

26. Hayashi, J., Ohta, S., Kikuchi, A., Takemitsu, M., Goto, Y., and Nonaka, I. (1991) Proc. Natl. Acad. Sci. U. S. A. 88, 10614-10618.

27. Bunn, C.L., Wallace, D.C., and Eisenstadt, J.M. (1977) Somatic. Cell Genet. 3, 71-92. 